\title{
Fetal Estetrol (E4) Inhibits Growth Hormone (GH) Signal Transduction in Breast Cancer Cell Lines
}

\author{
C Verhoeven', EPM Timmermans-Sprang², J S \\ Liu $^{2}$, A Gracanin ${ }^{2}$, HJ T Coelingh-Bennink ${ }^{1}$, JA \\ Mol $^{2 *}$ \\ ${ }^{1}$ Pantarhei Oncology, The Netherlands \\ ${ }^{2}$ Department of Clinical Sciences of Companion Animals, \\ Utrecht University, The Netherlands \\ *Corresponding author: J an A Mol, Department \\ of Clinical Sciences of Companion Animals, Utrecht \\ University, Yalelaan 104, 3584 CM Utrecht, The \\ Netherlands
}

Received: September 05, 2018; Accepted: October 01, 2018; Published: October 08, 2018

\begin{abstract}
Objective: Inhibition of GH signaling has been associated with increased longevity and cancer resistance. As the fetal estrogen estetrol was also linked to longevity and cancer resistance, we hypothesized that these effects of estetrol are mediated by inhibition of $\mathrm{GH}$ activity.

Design: The CNMm-6TR mammary cell line, stably transfected with doxycycline (DOX)-inducible GHR (CNMm-cGHR cells), HEK293 cell line transfected with rGHR and the human T47D cell line were used to assess effects of estetrol on $\mathrm{GH}$ signal transduction. Proliferation was measured using the colorimetric 3-[4,5-dimethylthiazol-2-yl]-2,5-diphenyltetrazolium bromide assay (MTT). Spi-luciferase reporter activity, responsive to phosphorylated Stat5, was used to assess $\mathrm{GH}$ signaling. GHR mRNA expression was normalized to a reference gene.
\end{abstract}

Results: Treatment of CNMm-cGHR cells with $\mathrm{GH}$ resulted in decreased proliferation rates. No effect was seen by the co-inhibition with estetrol. Using the spi-luc reporter activity, it was shown that $\mathrm{GH}$ activates the GHR/Jak2/ Stat5 pathway. Estetrol partially inhibited this activation. In the HEK-rGHR cells, estetrol was able to inhibit the $\mathrm{GH}$ induced activation of the spi-luc reporter, but only in the presence of an ERa expression plasmid. Effects of estetrol on the expression of GHR mRNA was assessed in T47D cells, a cell-line expressing ER, PR and GHR under natural promoters. After incubation with estetrol, a mean 4-fold inhibition of GHR mRNA expression was observed.

Conclusion: Using different cell systems, it was shown that estetrol is able to inhibit GH signaling, a process dependent on the presence of the Estrogen Receptor (ER). Estetrol may therefore be used to inhibit $\mathrm{GH}$-induced effects on breast cancer proliferation.

Keywords: Estetrol; Breast Cancer; Growth Hormone; Growth Hormone Receptor; Growth Hormone Signal Transduction; Estrogen Receptor Alpha

\section{Introduction}

About $75 \%$ of human breast cancers are hormone receptor positive (Estrogen Receptor (ER), and Progesterone Receptor (PR)). Combined treatment of women with estrogens and progestin's results in a significant increased incidence of human breast cancer [1], whereas estrogen only decreases the incidence of $[2,3]$ and mortality [4] due to breast cancer.

Progesterone is a major stimulating factor in the pathogenesis of canine mammary carcinoma, resulting in increased local mammary expression of Growth Hormone (GH) mRNA [5,6]. The locally produced GH within the mammary gland under the influence of progesterone, is responsible for the expansions of canine mammary stem and progenitor cells when the mammary gland grows during puberty, pregnancy and lactation and also in the menstrual cycle when progesterone levels are higher [7]. In the human, during many menstrual cycles, development of mammary gland is affected by repeated exposure to progesterone and GH and this can eventually lead to an expanded progenitor cell population. Progenitor cells, being more proliferative, have a higher risk for transformation through oncogenic hits [8].
Progesterone effects on the local release of $\mathrm{GH}$ in the dog are mediated by binding to the Progesterone Receptor A (PR-A) isoform as the Progesterone Receptor $\mathrm{B}$ (PR-B) isoform in the dog lacks overall transcriptional activity due to mutations in the AF3 domain [9]. Also in humans, overexpression of the PR-A isoform is related to more aggressive carcinomas making the dog a valid model for human breast cancer $[7,8,10]$.

Besides the stimulated production and release of $\mathrm{GH}$ by progesterone, also the GH receptor (GHR) plays an essential role in human and canine recruitment of mammary stem cells and thereby stimulates both tumor regrowth and metastasis $[7,8]$. Inhibition of GH signaling is associated with increased longevity and decreased tumor formation [11-13], most outspoken seen in Laron dwarfism. It is therefore both in terms of healthy aging and prevention of tumorigenesis of interest to find compounds that inhibit GH signaling [13].

According to the so-called 'estrogen paradox' estrogens may both stimulate and inhibit breast cancer growth [14]. They may also modulate the GH axis [15]. Estrogens modulate GH Receptor (GHR) expression and activity in the liver [16] when administered
Austin J Obstet Gynecol - Volume 5 Issue 7 - 2018

Submit your Manuscript | www.austinpublishing group.com

Jan A Mol et al. (c) All rights are reserved
Citation: C Verhoeven, EPM Timmermans-Sprang, JS Liu, A Gracanin, HJT Coelingh-Bennink, JA Mol. Fetal Estetrol (E4) Inhibits Growth Hormone (GH) Signal Transduction in Breast Cancer Cell Lines. Austin J Obstet Gynecol. 2018; 5(7): 1123 
Table 1: Primers used for PCR amplifications.

\begin{tabular}{|c|c|c|}
\hline Gene & Forward & Reversed \\
\hline GH & 5'-CTGCTGCTCATCCAGTCGT-3' & 5'-CAGGTCCTTGAGCTTCTCGT-3' \\
\hline GHR (qRT-PCR) & 5'-GCGCATCCCAGAGTCTACA-3' & 5'-ACCATGACGAACCCCATCT-3' \\
\hline GHR (full length) & 5'-TATGGATCTCTGGCAGCTGCTGTT-3' & 5'-GAAAGGCTACGGCATGATTTTGTT-3' \\
\hline Rps19 & 5'-CCTTCCTCAAAAAGTCTGGG-3' 5'-GTTCTCATCGTAGGGAGCAAG-3' \\
\hline
\end{tabular}

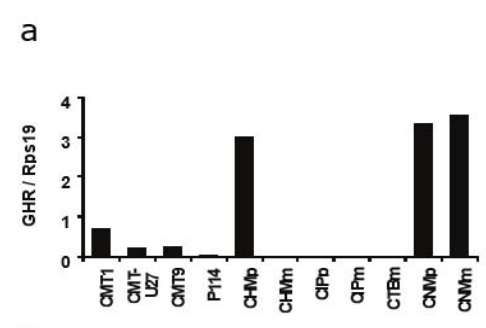

C

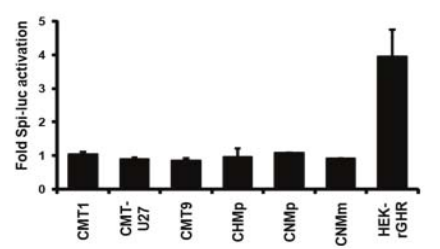

b

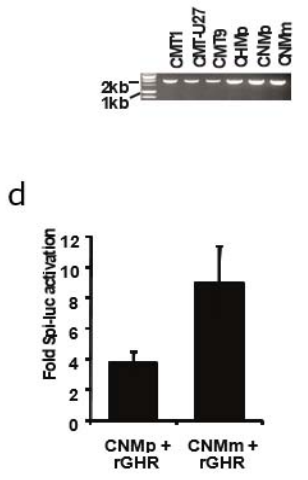

Figure 1: Expression of GHR mRNA in a panel of canine mammary tumo cell lines (a), PCR for full length GHR (b), and fold activation of spi-luc reporter activity in cell lines after incubation with $\mathrm{GH}$ (c), and after transient transfection with an rGHR construct (d).

orally. This results in decreased GH signal transduction in the liver by enhanced expression of suppressor of cytokine signaling 2 (SOCS2), an inhibitor of Janus kinase 2 (Jak2) activity, but in an increased expression of GHR.

Estetrol (E4), a natural human estrogen that is synthesized exclusively by the fetal liver during pregnancy, has recently been linked to longevity and cancer resistance [17]. We therefore hypothesize that E4 may function as an inhibitor of GH signaling within the mammary gland thereby protecting against breast cancer development or reducing its proliferative character.

\section{Materials and Methods}

\section{Cell lines}

Canine mammary cell lines used in this study were described previously [18-20] as was the generation of CNMm-6TR cell line [9]. The CNMm-6TR cells do not express a functional progesterone receptor but are positive for ERa. The cells were cultured on DMEM:F12 (Invitrogen, The Netherlands) supplemented with $10 \%$ FBS (FBS Gold, PAA). For generation of CNMm-6TR cell line with doxycycline (DOX)-inducible canine GHR (CNMmcGHR), full length coding region of cGHR was amplified from a cDNA pool of various canine mammary cell lines (using primer Fw 5'-ATGGATCTCTGGCAGCTGCTGTT-3' and Rv 5'-GAAAGGCTACGGCATGATTTTGTT-3') and cloned into pcDNA-4TO vector. CNMm-6TR cell line was subsequently transfected with pcDNA-4TO-cGHR using Lipofectamine 2000 (Invitrogen) and stably transfected cells were selected using DMEMF: 12 supplemented with $10 \%$ tetracycline negative (Tet-free) FBS
A

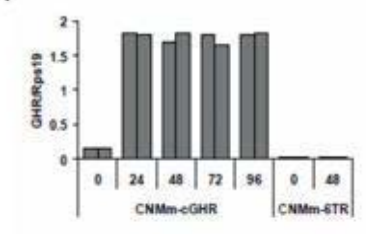

B

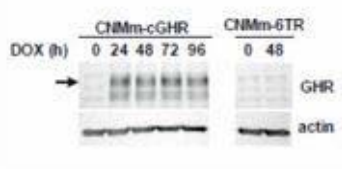

C

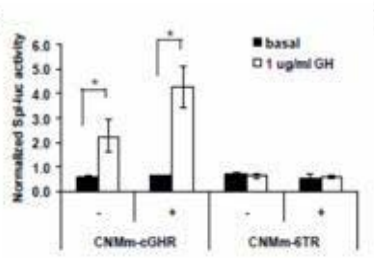

DFAs

Figure 2: Induction of cGHR expression in stable transfected CNMm-6TR cells with a cGHR construct before and after induction with doxycycline by qPCR (a) or Western blot (b). The reporter Spi-luciferase construct is activated only in CNMm-cGHR cells, although already some activation is seen without doxycycline (-) (c), and in Tet-free FBS (d). - indicates no DOX + indicates DOX treatment.

(PAA), $3 \mu \mathrm{g} / \mathrm{mL}$ blasticidin (Invitrogen) and $400 \mu \mathrm{g} / \mathrm{Ml}$ zeocin (Invitrogen). The HEK-rGHR cell line was a generous gift of Prof Ger Strous (UMCU, University of Utrecht, The Netherlands) [21]. The human T47D cell line was obtained from Prof Carol Sartorius [22].

\section{Transfections and luciferase assays}

Transfections for luciferase assays were performed as described before [9] using 0.8 $\mu \mathrm{g}$ Spi-luc reporter plasmid [23] that is responsive to phosphorylated Stat5. In case of co-transfection of canine cells with rabbit GHR (rGHR), cells were transfected with 10ng pcDNA3rGHR (gift from Prof. Ger Strous). HEK-rGHR cells were cotransfected with $0.8 \mu \mathrm{g}$ pCLneo-cER $\alpha$ (Canine ESR1, GenScript, Piscataway, USA). Cells were left to recover for $24 \mathrm{~h}$ in serum free medium, following by a treatment with $1 \mu \mathrm{g} / \mathrm{mL}$ porcine GH (Dr. A.F. Parlow, NHPP, USA). All transfection experiments were performed using three replicate samples and each experiment was independently repeated [2-4] times.

\section{RNA isolation and (quantitative) RT-PCR}

RNA isolation, cDNA synthesis and (quantitative) PCR were performed as described previously [9]. Information about the primers used for (quantitative) RT-PCR is shown in (Table I). Relative target gene expression was normalized to that of the reference gene RPS19 using a delta Ct method [24], and relative induction of gene expression was statistically tested using paired, two tailed Student's $t$ test in Microsoft Office Excel.

\section{Proliferation analysis (MTT)}

Cell proliferation was determined using the colorimetric 3-[4,5-dimethylthiazol-2-yl]-2,5-diphenyltetrazolium bromide 
assay (MTT) (Sigma, The Netherlands). Cells were seeded in 96 well plates at a density of 6,500 cells $/ 100 \mu \mathrm{l}$ and cultured in DMEM/F12 medium plus $5 \%$ Tet free charcoal stripped FBS. Cells were incubated for $24 \mathrm{~h}$ with medium alone (control) or in the presence of $10 \mu \mathrm{g} / \mathrm{mL}$ doxycycline, $1 \mu \mathrm{g} / \mathrm{mL}$ GH or the combination. After $24 \mathrm{~h}, 48 \mathrm{~h}$ and $72 \mathrm{~h}$ $20 \mu \mathrm{L}$ MTT was added in Hanks balanced salt solution and incubated for another $2 \mathrm{~h}$ at $37^{\circ} \mathrm{C}$. Then medium was removed, and cells were dissolved using $100 \mu \mathrm{L}$ DMSO. Finally, the absorbance was measured at $595 \mathrm{~nm}$ and plotted against the concentration of E4 added to the medium.

\section{Protein isolation and western blot}

To measure the effect of E2 and E4 on GH-activated GHR phosphorylation cells were incubated with $\mathrm{GH}$ in the absence or presence of $1 \mathrm{nM} \mathrm{E2}$ or $100 \mathrm{nM} \mathrm{E4}$. As controls cells were incubated without $\mathrm{GH}$, or with $\mathrm{GH}$ in the presence of $10 \mu \mathrm{M}$ of the JAK-inhibitor Apoquel (generous gift of Zoetis BV, Rotterdam, The Netherlands).

Protein isolation and western blotting was performed as described previously [9]. All steps were carried out on ice. For the isolation of total cellular protein cells were washed with HANK's balanced salt solution. Cell lysis was performed using RIPA (Lysis) buffer consisting of phosphate buffered saline ( $\mathrm{pH}$ 7.x), 1 \% Igepal, $0.5 \%$ sodium deoxycholate $(\mathrm{w} / \mathrm{v}), 0.1 \%$ SDS (v/v), $0.1 \mathrm{mg} / \mathrm{mL}$ PMSF, $15 \mu \mathrm{g} / \mathrm{mL}$ Aprotinin, and $0.1 \mathrm{mM}$ sodium orthovanadate. Cells were scraped with a scrubber and transferred to a cold Eppendorf tube and incubated for $30 \mathrm{~min}$ by end-over-end rotation at $4^{\circ} \mathrm{C}$. After centrifugation in a cooled centrifuge $\left(4^{\circ} \mathrm{C}\right)$ for $3 \mathrm{~min}$ at $1000 \mathrm{rpm}$ supernatants were pipetted carefully and stored for further use at $-20^{\circ} \mathrm{C}$. Protein concentration was measured using the $D C$ Protein Assay (BioRad Laboratories) and bovine serum albumin (BSA) as the standard.

For analysis of cGHR protein induction in CNMm-cGHR, cells were seeded in 6-well plates (Primaria) at 400,000 cells/well 24h prior to $24 \mathrm{~h}$ treatment with $1 \mu \mathrm{g} / \mathrm{mL}$ DOX (Sigma). Twenty $\mu \mathrm{g}$ of total cell lysates was subjected to SDS-PAGE and analyzed by Western blot using primary antibody against GHR ( $\alpha$ GHR, gift from Prof. G.J. Strous), anti-phosphotyrosine pY (Millipore 05-231, clone 4G10) or Pan actin (NeoMarkers/ Labvision, UK) and the secondary goat anti rabbit or goat anti mouse HRP-conjugated antibody (HAF008 or HAF007, respectively, R\&D Systems). HRP was visualized using AdvanceTM Enhanced chemiluminescence (ECL, Amersham, GE Healthcare) and analyzed using GelDoc2000 (BioRad, The Netherlands).

\section{Results}

\section{Assessment of $\mathrm{GH}$ and GHR expression in canine mammary tumor cell lines}

We initially screened a panel of canine mammary tumor cell lines for the expression of GH and GHR mRNA. All of canine mammary tumor cell lines had undetectable levels of GH mRNA (data not shown). Assessment of GHR mRNA expression showed differential levels of the transcript across the cell lines. A relatively high expression of GHR mRNA was detected in CHMp, CNMp and CNMm cell lines (Figure 1a).

Alternative transcripts of canine GHR have previously been reported [25] and resulted from different alternative processing of

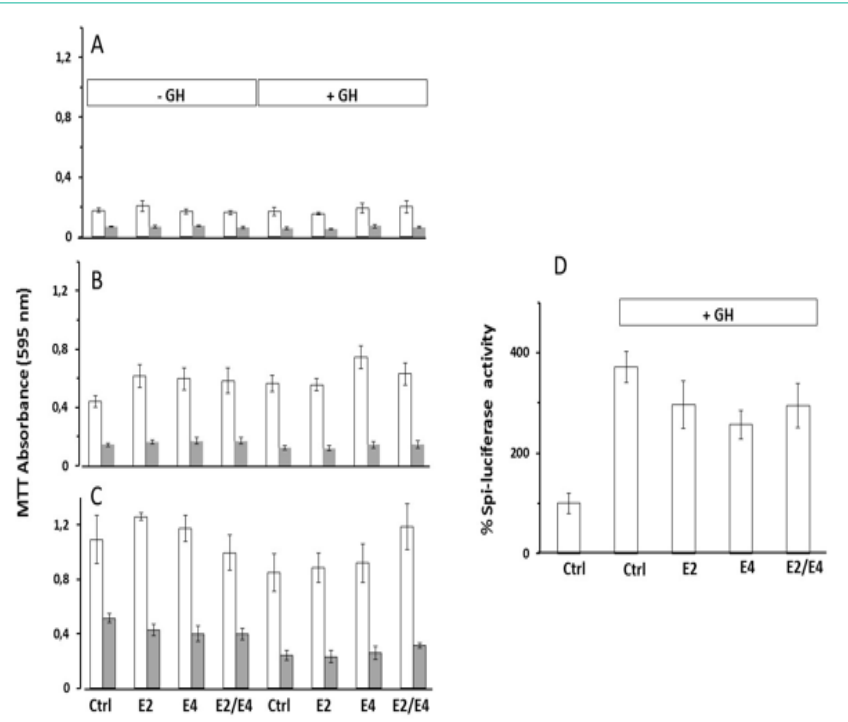

Figure 3: Proliferation of canine CNMm-cGHR cells. Cells were incubated for $24 \mathrm{~h}(\mathrm{~A}), 72 \mathrm{~h}(\mathrm{~B})$, or $144 \mathrm{~h}(\mathrm{C})$ with medium (Ctrl), $1 \mathrm{nM}$ E2, $100 \mathrm{nM}$ E4 or the combination of E2 and E4 in the absence or presence of $1 \mu \mathrm{g} / \mathrm{mL} \mathrm{GH}$. Cells were incubated in medium containing 10\% Tet-free FBS (open bars) or charcoal treated FBS devoid of steroids and growth factors (gray bars). (D) Spi-luc reporter gene activity. Incubation with $1 \mu \mathrm{g} / \mathrm{mL} \mathrm{GH}$ clearly stimulated Spi-luc activity which was partially inhibited using co-incubation with E2, E4 or the combination E2/E4.

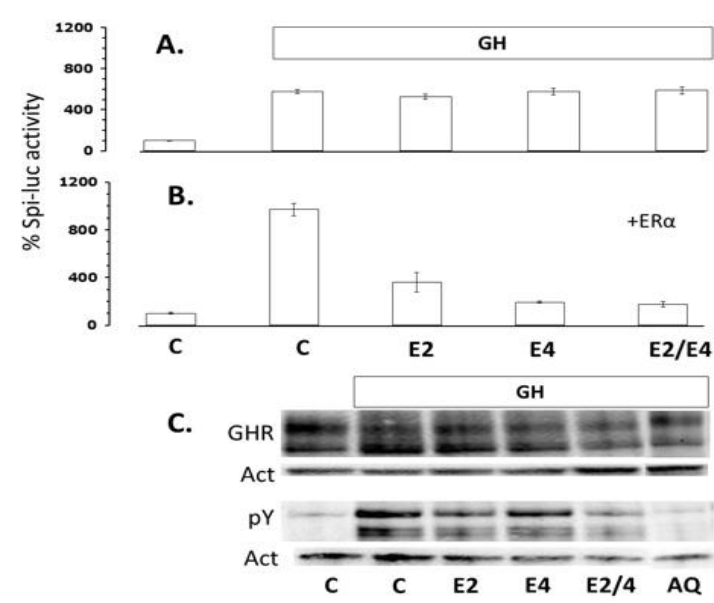

Figure 4: Spi-luc activity of HEK293-rGHR cells was greatly stimulated by incubation with $1 \mu \mathrm{g} / \mathrm{mL} \mathrm{GH}$, whereas no effect was seen of co-incubation of $\mathrm{GH}$ with $1 \mathrm{nM} E 2,100 \mathrm{nM} E 4$ or the combination (A) unless cells were transiently transfected using a canine ERa expression plasmid (B). In the presence of ERa almost complete inhibition of reporter activity was seen. Western blot analysis $(C)$ of the effect of E2, E4 or the combination on the protein expression of the GHR or GHR phosphorylation (pY) in HEK293 cells after stimulation with $\mathrm{GH}$. Medium without $\mathrm{GH}$ is taken as control, inhibition of GHR phosphorylation is done by incubation with the JAK1/2 inhibitor Apoquel (AQ). Actin (Act) expression is taken as loading control.

internal exons 6-9. Primers used to quantify GHR transcript amplify region of exon 2 and 3 and are therefore unable to discriminate between different GHR transcripts. To check for expression of alternative GHR transcripts, PCR was performed using primers that should amplify the whole coding region of GHR. Only the fulllength transcript of $1924 \mathrm{bp}$ was detected in the analyzed cell lines implying that the overall majority of transcripts are full length (Figure 


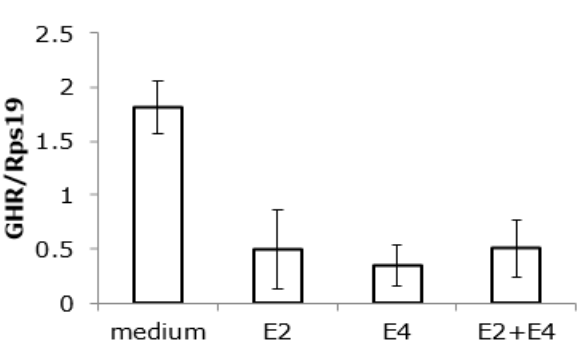

Figure 5: Effects of 1nM E2, $100 \mathrm{nM} \mathrm{E4}$ or the combination on the expression of GHR mRNA in T47D cells. Both estrogens inhibited the relative expression of the GHR mRNA in comparison to the expression of reference gene Rps19.

1b). Nonetheless, we were unable to detect the expression of GHR protein in the whole cell lysates of the cell lines (data not shown). To alternatively test for the expression of functional GHR protein, cell lines were transiently transfected with Spi-luc reporter that is responsive to phosphorylated Stat5 protein [23] and thereby to activation of GHR. HEK cell line stably expressing rabbit GHR (HEKrGHR) responded to treatment with exogenous $\mathrm{GH}$, while none of the tested canine mammary cell lines showed enhanced Spi-luc reporter activity (Figure 1c). Upon transient transfection with rGHR, CNMp and CNMm cell lines were able to respond to GH treatment (Figure 1d) implicating insufficient levels of endogenous functional GHR protein in the regarding cell lines.

In order to generate a canine mammary cell line model responsive to GH, the CNMm-6TR cell line was stably transfected with DOXinducible canine GHR (CNMm-cGHR). Induction of GHR mRNA (Figure 2) and protein (Figure 2) was detectable and stable for a period of 24 to 96 hours after doxycycline treatment, almost absent in the non-transfected CNMm-6TR cells, and low before doxycycline treatment. Moreover, upon induction of GHR, cells were responsive to $\mathrm{GH}$ treatment as measured by Spi-luc reporter transactivation (Figure 2). Of note, even in the absence of DOX treatment transfected GHR was expressed at low levels (Figure 2c) left, sufficient to render cells responsive to GH (Figure 2). Using Tet-free fetal bovine serum the basal Spi-luc reporter activity was greatly reduced (Figure 2).

\section{Effect of E4 on CNMm-cGHR cells}

The effects of incubation of the CNMm-cGHR cells with the estrogens E2, E4 or a combination of E2 and E4 in the absence or presence of GH were investigated. Cell viability was measured using a MTT assay (Figure 3). No effect was seen of doxycycline addition on the proliferation rate (not shown) so all further experiments were done in the presence of doxycycline to induce GHR expression.

The proliferation rate was much higher in the presence of $10 \%$ untreated Tet-free FBS in comparison with the FBS that was stripped using charcoal. No major differences were seen in the proliferation rates, with a small increased proliferation after addition of E2 or E4 only in the incubation with complete FBS. Treatment with GH resulted in decreased proliferation rates after $144 \mathrm{~h}$ incubation, whereas addition of estrogens had either no effect (estrogens alone) or showed some lifting of the $\mathrm{GH}$-induced decreased proliferation rates (E2/E4 combination).

Next the effect of estrogens were tested on GH-induced activation of a Spi-luc reporter construct that is activated by phosphorylated
Stat5 protein. GH stimulated almost 4 -fold the reporter activity (Figure 3 ) that was partially inhibited by co-incubation with the estrogens alone or in combination.

\section{Effect of E4 on HEK cells transfected with rGHR}

To demonstrate that the effects of estrogens on GH-induced activation of the GHR-JAK2-Stat5 signal transduction cascade were indeed mediated by the estrogen receptor, a HEK293 cell line stably transfected with rGHR was used. These cells do not express the estrogen receptor $(E R \alpha)$ endogenously. Incubation of these cells with GH showed a great stimulation of the Spi-luc reporter activity upon $\mathrm{GH}$-treatment. Co-incubation with E2, E4 or the combination did not affect the reporter activity (Figure 4 ). However, after transient cotransfection with a canine ERa expression plasmid, almost complete inhibition of reporter activity by both E2 and E4 was noticed (Figure 4).

The same HEK293 cell line that has high rGHR expression was used to assess the effect on the stability of the GHR and the phosphorylation of the GHR (Figure 4). Some decrease in GHR content was seen especially after incubation in the presence of both E2 and E4. Phosphorylation of the GHR was greatly enhanced by GH stimulation, an effect that could be inhibited by using the JAK inhibitor Apoquel (AQ). E2 and the combination of E2 and E4 showed partial inhibition of GHR phosphorylation (Figure 4). The expression of the GHR mRNA in the HEK293-rGHR and CNMmcGHR, however, is under an artificial promoter, reason that nothing can be said about effect on normal GHR expression. To study this the human T47D mammary carcinoma cell line was used, which expresses ER, PR and GHR.

\section{Effect of E4 on T47D cells}

In contrast to results reported in the literature we could not find a stimulatory effect of $\mathrm{E} 2$ or $\mathrm{GH}$ on the proliferation of T47D cells, neither after culture in complete $10 \%$ fetal calf serum, nor in charcoal treated serum (not shown). Also no effect was seen by incubation with E4 making this cell line less useful for the study of proliferation effects. However, these cells do express ER, PR and the GHR under natural promoters, and were used to see whether the estrogens have an effect on GHR mRNA expression. A mean 4-fold inhibition of GHR mRNA expression was found after incubation with E2, E4 or the combination (Figure 5).

\section{Discussion}

Oncogenic potential of progesterone in the canine mammary gland is suggested to involve induction of mammary GH expression. This locally produced GH has a dual effect on mammary gland proliferation exerted by the presence of GH receptor on mammary stem cells and on cells in the stromal compartment [7]. With respect to mammary stem cells, GH is thought to stimulate early recruitment whereas in the stromal compartment GH induced IGF-I production is involved in further clonal expansion and proliferation. Apart from locally produced $\mathrm{GH}$, having autocrine and paracrine working mechanisms within the mammary gland, also systemic GH plays an important role as endocrine stimulator of IGF-I production. Both GH and IGF-I play important roles in longevity and tumor progression [26]. Low plasma GH and IGF-I concentrations are associated with enhanced longevity and reduced tumor formation making 
the mechanism of GH-signaling an important target in oncology and healthy aging [13]. Estetrol (E4) has also been associated with increased longevity and cancer resistance [17]. We therefore tested in this study our hypothesis that the effects of $\mathrm{E} 4$ are mediated by inhibition of GH-induced GHR activation.

As no normal canine mammary cell lines were available to test this model, a panel of canine mammary tumor cell lines was screened for their activity and responsiveness of GH signaling. None of the tested cell lines expressed GH mRNA. This is a rather surprising observation, regarding the fact that the majority of mammary tumor tissues were shown to express GH [27]. Loss of GH expression upon generation of cell line cultures has been previously observed even in case of tumors with a high expression of GH (E. van Garderen, personal communication). Similarly, all cell lines differentially expressed GHR mRNA, but lacked the responsiveness to GH due to insufficient levels of functional GHR protein. Additional attempts to detect unprocessed GHR protein in whole cell lysates using biotinylated human GH failed due to low affinity of human GH for canine GHR protein (data not shown). Moreover, GHR expression and signaling have previously been detected and studied in CMT-U335 cell line [28]. We additionally tested the responsiveness of this cell line using Spi-luc reporter and were unable to confirm previously published results (data not shown). The discrepancy may come from the fact that the previous study relied on immunocytochemical staining for GHR and phosphorylation of Stat5a and Stat5b upon GH treatment on western blot of immunoprecipitated Stat proteins using a general antiphosphotyrosine antibody [28] whereas we used a Spi-luc reporter.

To generate a canine mammary cell line responsive to $\mathrm{GH}$ stimulation, CNMm tumor cell line was stably transfected with DOX-inducible canine GHR. Using this cell line we tested whether E4 can influence GH-signaling by measuring proliferation and Spi-luc reporter activity. In contrast with the expected increase in proliferation we did find a limited inhibition of cell proliferation in these cells after GH-stimulation. The estrogenic compounds E2 and $\mathrm{E} 4$ alone or in combination showed no or a limited increase in cell proliferation and partially reversed the surprisingly GH-induced inhibition of cell proliferation. In the generated CNMm cell line with inducible cGHR expression, combined DOX and GH treatment did not stimulate IGF-1 expression (data not shown). In MCF-7 mammary carcinoma cells, it is shown that IGF-I greatly enhances the proliferative effect of E2 $[29,30]$. We therefore assume that the tested effects of GH in this study were only direct and related to limited differentiation effects. Using the Spi-luciferase reporter, sensitive to activated phosphorylated-Stat5, we do show that GH activates the GHR/JAK2/Stat5 and that the estrogens partially inhibit this activation.

Using the HEK-rGHR cells again, and more outspoken, the estrogens inhibit the activation of the Spi-luc reporter, but only after co-transfection with a canine ER-alpha expression plasmid, showing that the inactivation of GH signaling by estrogens is totally dependent on the presence of the ER. No differences were found with respect to this between E2 and E4. Also no difference was found when both compounds were used together. Obviously, with respect to GH signaling, both estrogens show an identical working mechanism and no indications were found that E4 would antagonize E2-induced
ER activity [31,32]. As we do not know whether our HEK293 cells have membrane estrogen receptors from the nonappearance of an effect in the absence of the nuclear ER-alpha no conclusions can be drawn on possible divergent effects by other mechanisms [33]. Western blot analysis of GHR expression and phosphorylation in the HEK293-rGHR cells point to a decreased stability of the GHR protein and phosphorylation in the presence of E2 and E4, but by far not as strong as inhibition by the JAK inhibitor Apoquel and needs further consideration. In the CNMm-cGHR and HEK293-rGHR cell lines the expression of the GHR is under an artificial promoter and therefore GHR mRNA influences cannot be studied. However, preliminary studies in T47D cells, expressing GHR under natural promoters, also showed that GHR mRNA expression is negatively influenced by the estrogens, indicating an additional inhibiting effect on GH signaling.

Both E2 and E4 appeared to be inhibitors of GH-signaling. As low plasma GH and IGF-I concentrations are important regulators of longevity and cancer resistance, inhibition of GH signaling will be beneficial for healthy aging and decreased tumor formation. For estrogens, this will only work in those cells that co-express both GHR and ER. So far, no expression of ER has been shown in mammary stem cells, but in luminal progenitor cells the highest copy numbers of ER are found relative to unsorted cells or fully differentiated cells [34], and may therefore present cells that can be sensitive to GHR inhibition by estrogens. There is an ongoing discussion on the role of estrogens in female reproductive cancers [35,36]. For breast cancer treatment both anti-estrogens and estrogens can be effective under specific circumstances [13]. The data from this study suggest that the effect of estrogens may be mediated via inhibition of GH signaling. Apart from its effect on breast cancer progression $\mathrm{GH}$ excess is also related to a hypercoagulable state [37]. It needs to be further investigated whether the protection from arterial and venous thrombosis by E4 in mice [38] is also caused by inhibition of GH/ GHR signaling.

\section{Acknowledgement}

The contribution of Jeroen Vis in the preparation of CNMm6TR-cGHR cells is greatly acknowledged.

\section{References}

1. Chlebowski RT, Hendrix SL, Langer RD, Stefanick ML, Gass M, Lane D, et al. Influence of estrogen plus progestin on breast cancer and mammography in healthy postmenopausal women: the Women's Health Initiative Randomized Trial. 2003; 289: 3243-3253.

2. LaCroix AZ, Chlebowski RT, Manson JE, Aragaki AK, Johnson KC, Martin L, et al. Health outcomes after stopping conjugated equine estrogens among postmenopausal women with prior hysterectomy: a randomized controlled trial. 2011; 305: 1305-1314.

3. Anderson GL, Chlebowski RT, Aragaki AK, Kuller LH, Manson JE, Gass M, et al. Conjugated equine oestrogen and breast cancer incidence and mortality in postmenopausal women with hysterectomy: extended follow-up of the Women's Health Initiative randomised placebo-controlled trial. Lancet Oncol. 2012; 13: 476-486

4. Manson JE, Aragaki AK, Rossouw JE, Anderson GL, Prentice RL, LaCroix $A Z$, et al. Menopausal Hormone Therapy and Long-term All-Cause and Cause-Specific Mortality: The Women's Health Initiative Randomized Trials. JAMA. 2017; 318: 927-938.

5. Selman PJ, Mol JA, Rutteman GR, van Garderen E, Rijnberk A. Progestininduced growth hormone excess in the dog originates in the mammary gland. Endocrinology. 1994; 134: 287-292. 
6. Mol JA, van Garderen E, Selman PJ, Wolfswinkel J, Rijinberk A, Rutteman GR. Growth hormone mRNA in mammary gland tumors of dogs and cats. J Clin Invest. 1995; 95: 2028-2034.

7. Timmermans-Sprang EPM, Gracanin A, Mol JA. Molecular Signaling of Progesterone, Growth Hormone, Wnt, and HER in Mammary Glands of Dogs Rodents, and Humans: New Treatment Target Identification. Front Vet Sci. 2017; 4: 53.

8. Lombardi S, Honeth G, Ginestier C, Shinomiya I, Marlow R, Buchupalli $\mathrm{B}$, et al. Growth hormone is secreted by normal breast epithelium upon progesterone stimulation and increases proliferation of stem/progenitor cells. Stem Cell Reports. 2014; 2: 780-793.

9. Gracanin A, van Wolferen ME, Sartorius CA, Brenkman AB, Schoonen WG Mol JA. Canid progesterone receptors lack activation function 3 domaindependent activity. Endocrinology. 2012; 153: 6104-6113.

10. Nguyen F, Pena L, Ibisch C, Loussouarn D, Gama A, Rieder N, et al. Canine invasive mammary carcinomas as models of human breast cancer. Part 1 : natural history and prognostic factors. Breast Cancer Res Treat. 2018; 167 635-648.

11. Bartke A, Sun LY, Longo V. Somatotropic signaling: trade-offs between growth, reproductive development, and longevity. Physiol Rev. 2013; 93 571-598.

12. Junnila RK, List EO, Berryman DE, Murrey JW, Kopchick JJ. The GH/IGF-1 axis in ageing and longevity. Nat Rev Endocrinol. 2013; 9: 366-376.

13. Perry JK, Wu ZS, Mertani HC, Zhu T, Lobie PE. Tumour-Derived Human Growth Hormone as a Therapeutic Target in Oncology. Trends Endocrinol Metab. 2017; 28: 587-596.

14. Coelingh Bennink HJ, Verhoeven C, Dutman AE, Thijssen J. The use of highdose estrogens for the treatment of breast cancer. Maturitas. 2017; 95: 11-23.

15. Birzniece $\mathrm{V}$, Ho KKY. Sex steroids and the GH axis: Implications for the management of hypopituitarism. Best Pract Res Clin Endocrinol Metab. 2017 31: $59-69$

16. Fernandez-Perez L, Guerra B, Diaz-Chico JC, Flores-Morales A. Estrogens regulate the hepatic effects of growth hormone, a hormonal interplay with multiple fates. Front Endocrinol (Lausanne). 2013; 4: 66.

17. Kroll J. Estetrol, molecular chaperones, and the epigenetics of longevity and cancer resistance. Rejuvenation Res. 2014; 17: 157-158.

18. Hellmen E. Characterization of four In vitro established canine mammary carcinoma and one atypical benign mixed tumor cell lines. In vitro Cell Dev Biol. 1992; 28: 309-319.

19. Van Leeuwen IS, Cornelisse CJ, Misdorp W, Goedegebuure SA, Kirpensteijn J, Rutteman GR. P53 gene mutations in osteosarcomas in the dog. Cancer Lett. 1997; 111: 173-178.

20. Uyama R, Nakagawa T, Hong SH, Mochizuki M, Nishimura R, Sasaki N. Establishment of four pairs of canine mammary tumour cell lines derived from primary and metastatic origin and their E-cadherin expression. Vet Comp Oncol. 2006; 4: 104-113.

21. Putters J, da Silva Almeida AC, van Kerkhof $P$, van Rossum AG, Gracanin A Strous GJ. Jak2 is a negative regulator of ubiquitin-dependent endocytosis of the growth hormone receptor. PLoS One. 2011 Feb 9 ; 6: e14676.

22. Sartorius CA, Groshong SD, Miller LA, Powell RL, Tung L, Takimoto GS, et al. New T47D breast cancer cell lines for the independent study of progesterone B- and A-receptors: only antiprogestin-occupied B-receptors are switched to transcriptional agonists by cAMP. Cancer Res. 1994; 54: 3868-3877.
23. Wood TJ, Sliva D, Lobie PE, Goullieux F, Mui AL, Groner B, et al. Specificity of transcription enhancement via the STAT responsive element in the serine protease inhibitor 2.1 promoter. Mol Cell Endocrinol. 1997; 130: 69-81.

24. Livak KJ, Schmittgen TD. Analysis of relative gene expression data using real-time quantitative PCR and the 2(-Delta Delta C(T)) Methods. 2001; 25: 402-408.

25. Van Garderen E, van der Poel HJ, Swennenhuis JF, Wissink EH, Rutteman $\mathrm{GR}$, Hellmen $\mathrm{E}$, et al. Expression and molecular characterization of the growth hormone receptor in canine mammary tissue and mammary tumors. Endocrinology. 1999; 140: 5907-5914.

26. Subramani R, Nandy SB, Pedroza DA, Lakshmanaswamy R. Role of Growth Hormone in Breast Cancer. Endocrinology. 2017; 158: 1543-1555.

27. Van Garderen E, Schalken JA. Morphogenic and tumorigenic potentials of the mammary growth hormone/growth hormone receptor system. Mol Cell Endocrinol. 2002; 197: 153-165.

28. Van Garderen E, Swennenhuis JF, Hellmen E, Schalken JA. Growth hormone induces tyrosyl phosphorylation of the transcription factors Stat5a and Stat5b in CMT-U335 canine mammary tumor cells. Domest Anim Endocrinol. 2001; 20: 123-135.

29. Van der Burg B, Isbrucker L, van Selm-Miltenburg AJ, de Laat SW, van Zoelen EJ. Role of estrogen-induced insulin-like growth factors in the proliferation of human breast cancer cells. Cancer Res. 1990; 50: 7770-7774.

30. Dupont J, Le Roith D. Insulin-like growth factor 1 and oestradiol promote cell proliferation of MCF-7 breast cancer cells: new insights into their synergistic effects. Mol Pathol. 2001; 54: 149-154.

31. Gerard C, Mestdagt M, Tskitishvili E, Communal L, Gompel A, Silva E, et al. Combined estrogenic and anti-estrogenic properties of estetrol on breast cancer may provide a safe therapeutic window for the treatment of menopausal symptoms. Oncotarget. 2015; 6: 17621-17636.

32. Gerard C, Blacher S, Communal L, Courtin A, Tskitishvili E, Mestdagt M, et al. Estetrol is a weak estrogen antagonizing estradiol-dependent mammary gland proliferation. J Endocrinol. 2015; 224: 85-95.

33. Abot A, Fontaine C, Buscato M, Solinhac R, Flouriot G, Fabre A, et al The uterine and vascular actions of estetrol delineate a distinctive profile of estrogen receptor alpha modulation, uncoupling nuclear and membrane activation. EMBO Mol Med. 2014; 6: 1328-1346.

34. Hilton HN, Clarke CL. Impact of progesterone on stem/progenitor cells in the human breast. J Mammary Gland Biol Neoplasia. 2015; 20: 27-37.

35. Brown SB, Hankinson SE. Endogenous estrogens and the risk of breast, endometrial, and ovarian cancers. Steroids. 2015; 99: 8-10.

36. Chuffa LG, Lupi-Junior LA, Costa AB, Amorim JP, Seiva FR. The role of sex hormones and steroid receptors on female reproductive cancers. Steroids. 2017; 118: 93-108.

37. Erem C, Nuhoglu I, Kocak M, Yilmaz M, Sipahi ST, Ucuncu O, et al. Blood coagulation and fibrinolysis in patients with acromegaly: increased plasminogen activator inhibitor-1 (PAl-1), decreased tissue factor pathway inhibitor (TFPI), and an inverse correlation between growth hormone and TFPI. Endocrine. 2008; 33: 270-276.

38. Valera MC, Noirrit-Esclassan E, Dupuis M, Fontaine C, Lenfant F, Briaux A et al. Effect of estetrol, a selective nuclear estrogen receptor modulator, in mouse models of arterial and venous thrombosis. Mol Cell Endocrinol. 2018; 477: 132-139.
Austin J Obstet Gynecol - Volume 5 Issue 7 - 2018 Submit your Manuscript | www.austinpublishinggroup.com Jan A Mol et al. () All rights are reserved
Citation: C Verhoeven, EPM Timmermans-Sprang, JS Liu, A Gracanin, HJT Coelingh-Bennink, JA Mol. Fetal Estetrol (E4) Inhibits Growth Hormone (GH) Signal Transduction in Breast Cancer Cell Lines. Austin J Obstef Gynecol. 2018; 5(7): 1123 